\title{
Characterization of Doubled Walled Carbon Nanotubes using Finite Element Method
}

\author{
K. Vidyasagar \\ Dept. of ECE, SSIT,Sathupally,
}

T.S, India

\author{
Sk. Ahmad Saidulu \\ Dept. of ECE, SSIT,Sathupally, \\ T.S, India
}

\author{
T. Chaitanya \\ Dept. of ECE, SSIT,Sathupally, \\ T.S, India
}

\begin{abstract}
Nano composites will be developed using carbon nanotubes (CNTs). When compared with the conventional carbon fibers, CNTs in polymer matrices enhance the stiffness and strength of composites. The work is focused on the Double walled carbon nanotubes (DWCNTs) to investigate the mechanical properties. Modulus of elasticity is considered to analyze the behavior of CNTs by adopting the Finite element model (FEM). The experiments conducted on both armchair and zigzag Nanotubes. By considering the length and radius of the inner and outer tubes of CNTs, the developed stress with the applied load, strain and young's modulus and its response to the load applied is estimated using FEM. The influence of external vibrations on the CNTs considerably minimized with significant stiffness constant $(\mathrm{K})$ of the CNTs. The results obtained are supportive to analyze the behavior of CNTs.
\end{abstract}

\section{Keywords}

CNTs, DWCNTs, FEM, Stress, strain, young's modulus.

\section{INTRODUCTION}

In recent developments the technology is focusing on the Nanotubes, and Nano materials. Considering the elasticity and ductileness, Nanotubes are having its unique significance in medical, water purification and in defense applications. Space frame like structure is simulated using nano tube modular software. The Connecting atoms act as joints for carbon nanotubes. The covalent bond between the carbon atoms considered as connecting elements. The bonds between the carbon atoms modeled as elastic beam elements. For analyzing the nano tubes FEM and molecular dynamics (MD) tools are widely used. Carbon nanotubes are classified as single walled carbon nanotubes (SWCNTS) and multi walled carbon nanotubes (MWCNTs). A thin graphite sheet rolled into a cylindrical shape, a hallow structure is formed by the carbon atoms with covalently bonded. The end caps (hemispherical caps) used to seal both ends of the CNTs. Long continuous CNTs can be formed by neglecting the end caps and considering the length to diameter aspect ratio.

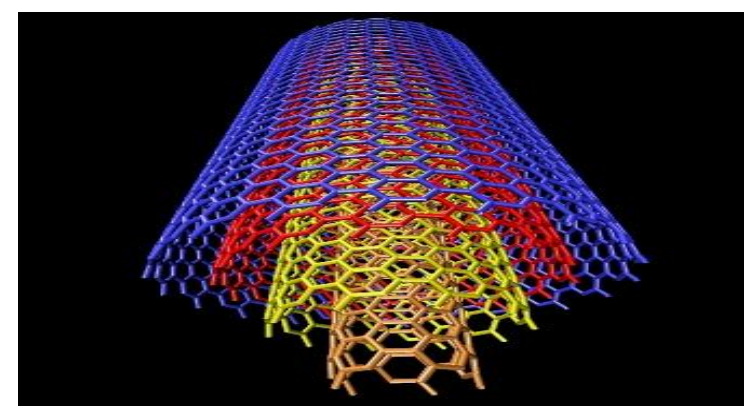

Fig.1 Multi walled carbon nanotube

Fig.1 Represents the Multi walled carbon nanotubes formed by rolling the Graphite sheets coaxially. The angle subtended by rolling the graphite sheet may form armchair representing the fig.2, Zig-Zag (Fig.3), Chiral type of nanotubes. A Vector $(n, m)$ is used to describe the structure of the Nanotubes. For all Zig-Zag tubes the indices $m=0$, for all armchair tubes $n=m$ and for all chiral tubes $n, m$ are different.

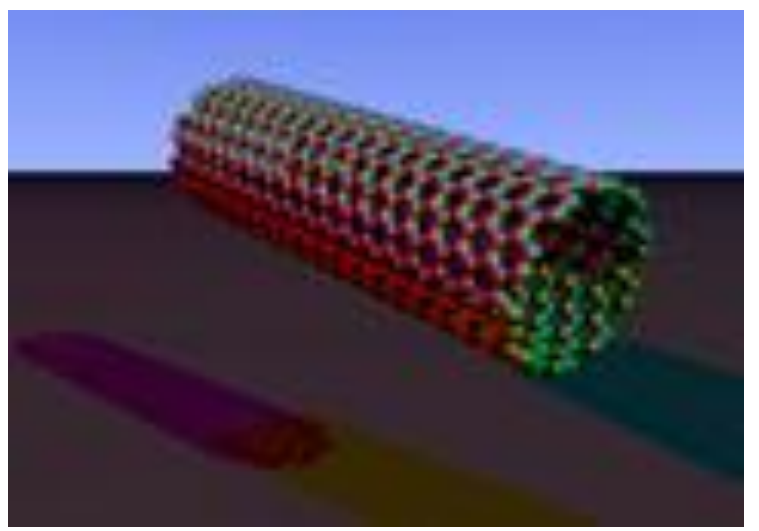

Fig 2. Armchair nanotube with indices (n,n)

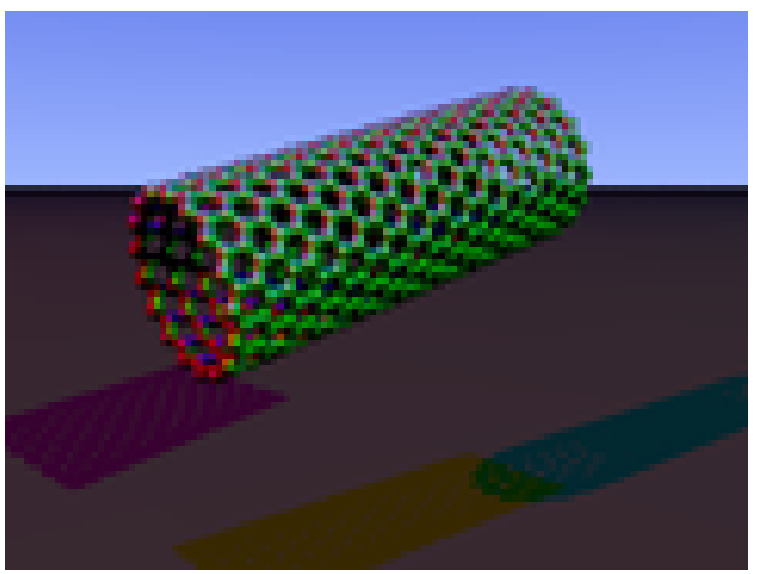

Fig.3 Zig-Zag nanotube with indices $(\mathbf{n , 0})$

Continuum mechanics - Finite Elelment Method of technique is an effective approach to estimate the properties of the Nanotubes. The distribution of stress on CNTs and its structural bend, twist is analysed using the proposed FEM. By adopting the FEM the modulus of elasticity for different lengths of the tubes for both armchair and Zig-Zag carbon Nanotubes are observed.

\section{LITERATURE SURVEY}

This work focused on mass sensing of double walled carbon nanotubes using finite element model. By changing its length and masses the resonant frequency shift of the double walled carbon nanotubes (DWCNTs) changes [1].

The resonant frequencies and its vibration of double walled carbon nanotube are studied using gradient smoothing technique. By considering the intertube vanderwall interaction 
Euler beam theory is applied to study the double elastic beam [2].

Three dimensional armchair, Zig-Zag and chiral type carbon nanotubes for both single tube and multi tubes are modeled using finite element modeling method. This study concluded that the young's modulus is larger for chiral than the zig-zag and armchair tubes [3].

This paper focused to study the free vibration analysis of double walled carbon nanotubes based on nonlocal elasticity theory. Considering the Timoshenko beam theory the effect of transverse shear deformation and rotary inertia is analyzed [4].

This study adopted a finite element modeling for analyzing the large amplitude vibrations on Double walled carbon nanotubes. This study stated that the non linear frequencies are obtained apparently for the first time with different boundary conditions [5].

This study focused on interlayer separation of vander walls interaction. This study modeled a nanotube by considering a spring element used as an elastic beam connecting the inner and outer walls of the nanotubes . [6].

Methodology

Declaration of parameters of carbon nanotubes

Parameters considered are:

$A=$ cross sectional are of the tube

$\mathrm{E}=$ Young's modulus

D0 $=$ Outer tube diameter

$\mathrm{Di}=$ Inner tube Diameter

$\mathrm{Tw}=$ wall thickness

L1 =Length of the inner tube

L2 = Length of the outer tube

\section{ESTIMATION OF THE PARAMETE- RS}

Step1: Fix the length of the tube with inner tube length greater than the length of the outer tube before applying the force on the tube.

Step 2: calculate the diameter of the tubes for the respective indices $(n, m)$.

Step3: the thickness of the nanotube is taken using previous experiments, $\mathrm{t} w=0.1296$ nano starins.

Step4. After considering all the parameters of the tube apply force in steps to deform the shape of the tube. Consider Force (F) in the range of $25-90 \mathrm{KN} / \mathrm{m} 2$ in steps of $5 \mathrm{KN} / \mathrm{m} 2$.

Step5. Estimate the stress using the formula

Stress $=$ Force $/$ area

Where, area $=\mathrm{pi} * \mathrm{~d} * \mathrm{t}$

$\mathrm{A} 1=$ outer tube cross-sectional area

$\mathrm{A} 1=\mathrm{pi} * \mathrm{D} 0 * \mathrm{tw}$

$\mathrm{A} 2=$ inner tube cross-sectional area

$\mathrm{A} 2=\mathrm{pi} * \mathrm{Di} * \mathrm{tw}$

D0, $\mathrm{Di}=$ diameter of the outer and inner tube respectively.
Step6. Strain is estimated using the formula

$$
\text { Strain }=\text { stress } * \text { Young's modulus }
$$

Step7. Using step 6 estimates the length of the CNT walls after load applied.

The final length of the two walls of the DWCNT is

$\mathrm{FL} 1=\mathrm{L} 1 *(1+\mathrm{e} 1)$

$\mathrm{FL} 2=\mathrm{L} 2 *(1+\mathrm{e} 2)$

L1 and L2 are initial outer and inner tube walls.

Step8. Bond length (W) of nanotube is $3.400 \mathrm{~A}$ is fixed using nano tube modeler.

Calculate the Moment of inertia using

$$
\mathrm{I}=\mathrm{W} * \mathrm{r} 3
$$

Where, $r=$ radius of the tube

By using the calculated value of moment of inertia, calculate the stiffness constant of the tube.

Stiffness constant, $\mathrm{K}=\mathrm{y}^{*} \mathrm{I} / \mathrm{L}$

Where $y=$ young's modulus

$\mathrm{L}=\mathrm{L} 2-\mathrm{L} 1=$ change in length

\section{RESULTS AND ANALYSIS}

It has been observed that by increasing the diameter of the naonotube, the stress developed on the tube is minimized proportionally. The strain developed on the tube is decreasing with increasing the tube length. The aspect ratio of length to radius is much influenced on the young's modulus of the double walled carbon nanotubes. With the increase of the aspect ratio of the DWCNT the young's modulus is increasing proportionally. With the increase of the radius of the tube the young's modulus is decreasing for arm chair DWCNTs. It is also observed that the young's modulus is inversely proportional to the stiffness constant of the DWCNTs. By doubling the Stiffness constant of the outer wall tube, the stress developed on the inner wall of the tube is having no influence on its young's modulus.

By fixing the tube length and significant amount of force applied on the tube in the longitudinal direction, considerable incremental change is observed on the outer tube rather than inner tube. It is also observed that the influence of the mechanical vibrations on the outer surface of the DWCNTs did not change the mechanical properties of the inner wall cylinder of the nanotube. And the buckling, bend of the DWCNT is limited to outer wall of the DWCNT only. By considering the stiffness constant to a considerable value, the load impact on the tube is minimized positively.

a) The mechanical properties estimated for Armchair DWCNTs using Finite Element method

Arm chair (n.n)

$\mathrm{L} 1=$ length of the inner tube

L2 = length of the outer tube

e $1=$ strain on the inner tube

e2 $=$ strain on the outer tube 
Table 1. Length Vs Strain values of a carbon nanotube.

\begin{tabular}{|c|c|c|c|c|}
\hline S.No & $\begin{array}{c}\text { Length } \\
\text { L1 }\end{array}$ & Strain( e1) & $\begin{array}{c}\text { Length } \\
\text { L2 }\end{array}$ & $\begin{array}{c}\text { Strain } \\
(\mathrm{e} 2)\end{array}$ \\
\hline 1 & 100 & 0.0015 & 150 & 0.0013 \\
\hline 2 & 130 & 0.0012 & 180 & 0.0011 \\
\hline 3 & 160 & 0.0009 & 210 & 0.0010 \\
\hline 4 & 190 & 0.0008 & 240 & 0.0008 \\
\hline 5 & 220 & 0.0007 & 270 & 0.0007 \\
\hline 6 & 250 & 0.0006 & 300 & 0.0007 \\
\hline 7 & 280 & 0.0005 & 330 & 0.0006 \\
\hline 8 & 310 & 0.0005 & 360 & 0.0006 \\
\hline 9 & 340 & 0.0004 & 390 & 0.0005 \\
\hline 10 & 370 & 0.0004 & 420 & 0.0005 \\
\hline
\end{tabular}

Table 2. Radius Vs Stress relationship of the CNTs

\begin{tabular}{|c|c|c|c|c|}
\hline $\begin{array}{l}\text { S. } \\
\text { No }\end{array}$ & $\begin{array}{l}\text { Radius ( } \\
\text { r1) }\end{array}$ & Stress (S1) & $\begin{array}{l}\text { Radius ( } \\
\text { r2) }\end{array}$ & $\begin{array}{l}\text { Stress } \\
(\mathrm{S} 2)\end{array}$ \\
\hline 1 & 1.9430 & 3.1765 & 3.8870 & 1.5878 \\
\hline 2 & 2.0930 & 2.9488 & 4.1870 & 1.4741 \\
\hline 3 & 2.2430 & 2.7516 & 4.4870 & 1.3755 \\
\hline 4 & 2.3930 & 2.5792 & 4.7870 & 1.2893 \\
\hline 5 & 2.5430 & 2.4270 & 5.0870 & 1.2133 \\
\hline 6 & 2.6930 & 2.2918 & 5.3870 & 1.1457 \\
\hline 7 & 2.8430 & 2.1709 & 5.6870 & 1.0853 \\
\hline 8 & 2.9930 & 2.0621 & 5.9870 & 1.0309 \\
\hline 9 & 3.1430 & 1.9637 & 6.2870 & 0.9817 \\
\hline 10 & 3.2930 & 1.8743 & 6.5870 & 0.9370 \\
\hline
\end{tabular}

Table3. Radius Vs Young's modulus

\begin{tabular}{|l|l|l|l|l|}
\hline $\begin{array}{l}\text { S. } \\
\text { No }\end{array}$ & $\begin{array}{l}\text { Radius } \\
(\mathrm{r} 1)\end{array}$ & $\begin{array}{l}\text { Young's } \\
\text { Modulus } \\
\text { (Y1) }\end{array}$ & $\begin{array}{l}\text { Radius } \\
(\mathrm{r} 2)\end{array}$ & $\begin{array}{l}\text { Young's } \\
\text { Modulus } \\
(\text { Y2) }\end{array}$ \\
\hline 1 & 1.9430 & 4.5378 & 3.8870 & 2.2683 \\
\hline 2 & 2.0930 & 3.6861 & 4.1870 & 1.8426 \\
\hline 3 & 2.2430 & 3.0574 & 4.4870 & 1.5283 \\
\hline 4 & 2.3930 & 2.5792 & 4.7870 & 1.2893 \\
\hline 5 & 2.5430 & 2.2064 & 5.0870 & 1.1030 \\
\hline 6 & 2.6930 & 1.9099 & 5.3870 & 0.9548 \\
\hline 7 & 2.8430 & 1.6699 & 5.6870 & 0.8348 \\
\hline 8 & 2.9930 & 1.4729 & 5.9870 & 0.7363 \\
\hline 9 & 3.1430 & 1.3091 & 6.2870 & 0.6445 \\
\hline 10 & 3.2930 & 1.1714 & 6.5870 & 0.5856 \\
\hline
\end{tabular}

b) The mechanical properties estimated for Zig-Zag DWCNTs using Finite Element method

For Zig-Zag ( n,0 )

Table4. Length Vs Strain

\begin{tabular}{|c|c|c|c|c|}
\hline S.No & $\begin{array}{c}\text { Length } \\
\text { (L1) }\end{array}$ & Strain (e1) & $\begin{array}{c}\text { Length } \\
\text { (L2) }\end{array}$ & Strain (e2) \\
\hline 1 & 100 & 0.7000 & 150 & 0.5333 \\
\hline 2 & 130 & 0.5385 & 180 & 0.4444 \\
\hline 3 & 160 & 0.4375 & 210 & 0.3810 \\
\hline 4 & 190 & 0.3684 & 240 & 0.3333 \\
\hline 5 & 220 & 0.3182 & 270 & 0.2963 \\
\hline 6 & 250 & 0.2800 & 300 & 0.2667 \\
\hline 7 & 280 & 0.2500 & 330 & 0.2424 \\
\hline 8 & 310 & 0.2258 & 360 & 0.2222 \\
\hline 9 & 340 & 0.2059 & 390 & 0.2051 \\
\hline 10 & 370 & 0.1892 & 420 & 0.1905 \\
\hline
\end{tabular}

Table5. Radius Vs Stress relationship

\begin{tabular}{|c|c|c|c|c|}
\hline S.No & Radius(r1) & Stress (S1) & Radius(r2) & Stress(S2) \\
\hline 1 & 0.3890 & 1.5866 & 3.8870 & 1.5878 \\
\hline 2 & 0.7780 & 0.7933 & 4.0950 & 1.5072 \\
\hline 3 & 1.1670 & 0.5289 & 4.3030 & 1.4343 \\
\hline 4 & 1.5560 & 0.3967 & 4.5110 & 1.3682 \\
\hline 5 & 1.9450 & 0.3173 & 4.7190 & 1.3079 \\
\hline 6 & 2.3340 & 0.2644 & 4.9270 & 1.2527 \\
\hline 7 & 2.7230 & 0.2267 & 5.1350 & 1.2019 \\
\hline 8 & 3.1120 & 0.1983 & 5.3430 & 1.1551 \\
\hline 9 & 3.5010 & 0.1763 & 5.5510 & 1.1119 \\
\hline 10 & 3.8900 & 0.1587 & 5.7590 & 1.0717 \\
\hline
\end{tabular}

Table6. Radius Vs Young's modulus

\begin{tabular}{|l|l|l|l|l|}
\hline $\begin{array}{l}\text { S. } \\
\text { No }\end{array}$ & $\begin{array}{l}\text { Radius } \\
\text { (r1 })\end{array}$ & $\begin{array}{l}\text { Young's } \\
\text { Modulus } \\
\text { (Y1) }\end{array}$ & $\begin{array}{l}\text { Radius } \\
\text { (r2) }\end{array}$ & $\begin{array}{l}\text { Young's } \\
\text { Modulus } \\
\text { (Y2) }\end{array}$ \\
\hline 1 & 0.3890 & 2.2666 & 3.8870 & 2.2683 \\
\hline 2 & 0.7780 & 0.9916 & 4.0950 & 1.8840 \\
\hline 3 & 1.1670 & 0.5876 & 4.3030 & 1.5937 \\
\hline 4 & 1.5560 & 0.3967 & 4.5110 & 1.3683 \\
\hline 5 & 1.9450 & 0.2885 & 4.7190 & 1.1890 \\
\hline 6 & 2.3340 & 0.2204 & 4.9270 & 1.0439 \\
\hline 7 & 2.7230 & 0.1744 & 5.1350 & 0.9246 \\
\hline 8 & 3.1120 & 0.1417 & 5.3430 & 0.8251 \\
\hline 9 & 3.5010 & 0.1175 & 5.5510 & 0.7412 \\
\hline 10 & 3.8900 & 0.0992 & 5.7590 & 0.6698 \\
\hline
\end{tabular}


Table 7. Stiffness constant Vs young's modulus

\begin{tabular}{|c|c|c|c|c|}
\hline $\begin{array}{c}\text { S. } \\
\text { No }\end{array}$ & $\begin{array}{c}\text { Stiffness } \\
\text { Coefficient } \\
(\mathrm{K} 1)\end{array}$ & $\begin{array}{c}\text { Young's } \\
\text { modulus } \\
(\mathrm{Y} 1)\end{array}$ & $\begin{array}{c}\text { Stiffness } \\
\text { Coefficient } \\
(\mathrm{K} 2)\end{array}$ & $\begin{array}{c}\text { Young's } \\
\text { modulus } \\
(\mathrm{Y} 2)\end{array}$ \\
\hline 1 & 9.0000 & 15.9000 & 2.3197 & 2.2716 \\
\hline 2 & 9.8100 & 17.3000 & 1.5961 & 1.5658 \\
\hline 3 & 10.6200 & 18.7000 & 1.3105 & 1.2877 \\
\hline 4 & 11.4300 & 20.1000 & 1.1416 & 1.1231 \\
\hline 5 & 12.2400 & 21.5000 & 1.0234 & 1.0080 \\
\hline 6 & 13.0500 & 22.9000 & 0.9332 & 0.9201 \\
\hline 7 & 13.8600 & 24.3000 & 0.8607 & 0.8494 \\
\hline 8 & 14.6700 & 25.7000 & 0.8005 & 0.7905 \\
\hline 9 & 15.4300 & 27.1000 & 0.7492 & 0.7404 \\
\hline 10 & 16.2900 & 28.5000 & 0.7049 & 0.6970 \\
\hline
\end{tabular}

Table 8. Estimated mechanical properties of the Armchair DWCNT with applied load

\begin{tabular}{|c|c|c|c|c|c|c|c|c|}
\hline S.No & $\begin{array}{c}\text { Radius } \\
\left(\mathrm{r}_{1}\right)\end{array}$ & $\begin{array}{c}\text { Radius } \\
\left(\mathrm{r}_{2}\right)\end{array}$ & $\begin{array}{c}\text { Area } \\
\left(\mathrm{A}_{1}\right)\end{array}$ & $\begin{array}{c}\text { Area } \\
\left(\mathrm{A}_{2}\right)\end{array}$ & $\mathrm{S}_{1}$ & $\mathrm{~S}_{2}$ & $\mathrm{e}_{1}$ & $\mathrm{e}_{2}$ \\
\hline 1 & 1.943 & 3.8870 & 0.4149 & 0.0830 & 6.0260 & 3.0122 & 4.8597 & 2.4292 \\
\hline 2 & 2.1730 & 4.2070 & 0.4640 & 0.0898 & 6.4658 & 3.3397 & 5.2144 & 2.6933 \\
\hline 3 & 2.4030 & 4.5270 & 0.5131 & 0.0967 & 6.8214 & 3.6209 & 5.5012 & 2.9201 \\
\hline 4 & 2.6330 & 4.8470 & 0.5622 & 0.1035 & 7.1149 & 3.8650 & 5.7378 & 3.1169 \\
\hline 5 & 2.8630 & 5.1670 & 0.6113 & 0.1103 & 7.3613 & 4.0788 & 5.9365 & 3.2894 \\
\hline 6 & 3.0930 & 5.4870 & 0.6604 & 0.1172 & 7.5710 & 4.2677 & 6.1056 & 3.4417 \\
\hline 7 & 3.3230 & 5.8070 & 0.7095 & 0.1240 & 7.7516 & 4.4358 & 6.2513 & 3.5773 \\
\hline 8 & 3.5530 & 6.1270 & 0.7586 & 0.1308 & 7.9089 & 4.5863 & 6.3782 & 3.6986 \\
\hline 9 & 3.7830 & 6.4470 & 0.8077 & 0.1377 & 8.6471 & 4.7219 & 6.4896 & 3.8080 \\
\hline 10 & 4.0130 & 6.7670 & 0.8569 & 0.1445 & 8.1694 & 4.8447 & 6.5882 & 3.9070 \\
\hline
\end{tabular}

Table 9. Estimated mechanical properties of the Zig-Zag DWCNT with applied load

\begin{tabular}{|c|c|c|c|c|c|c|c|c|}
\hline S.No & $\begin{array}{c}\text { Radius } \\
\left(\mathrm{r}_{1}\right)\end{array}$ & $\begin{array}{c}\text { Radius } \\
\left(\mathrm{r}_{2}\right)\end{array}$ & $\begin{array}{c}\text { Area } \\
\left(\mathrm{A}_{1}\right)\end{array}$ & $\begin{array}{c}\text { Area } \\
\left(\mathrm{A}_{2}\right)\end{array}$ & $\mathrm{S}_{1}$ & $\mathrm{~S}_{2}$ & $\mathrm{e}_{1}$ & $\mathrm{e}_{2}$ \\
\hline 1 & 1.9430 & 3.8870 & 0.4149 & 0.0830 & 6.0260 & 3.0122 & 4.8597 & 2.4292 \\
\hline 2 & 2.1660 & 4.1970 & 0.4625 & 0.0896 & 6.4867 & 3.3477 & 5.2312 & 2.6997 \\
\hline 3 & 2.3890 & 4.5070 & 0.5101 & 0.0962 & 6.8614 & 3.6370 & 5.5334 & 2.9331 \\
\hline 4 & 2.6120 & 4.8170 & 0.5577 & 0.1029 & 7.1721 & 3.8891 & 5.7840 & 3.1363 \\
\hline 5 & 2.8350 & 5.1270 & 0.6053 & 0.1095 & 7.4340 & 3.1107 & 5.9851 & 3.3150 \\
\hline 6 & 3.0580 & 5.4370 & 0.6529 & 0.1161 & 7.6576 & 4.3070 & 6.1755 & 3.4734 \\
\hline 7 & 3.2810 & 5.7470 & 0.7006 & 0.1227 & 7.8509 & 4.4821 & 6.3313 & 3.6146 \\
\hline 8 & 3.5040 & 6.0570 & 0.7482 & 0.1293 & 8.0695 & 4.6393 & 6.4675 & 3.7414 \\
\hline 9 & 3.70 & 6.3670 & 0.7958 & 0.1359 & 8.1680 & 4.7812 & 6.5871 & 3.8558 \\
\hline 10 & 3.9500 & 6.6770 & 0.8434 & 0.1426 & 8.2997 & 4.9100 & 6.6933 & 3.9596 \\
\hline
\end{tabular}


Table 10. Estimated final length with developed strain

\begin{tabular}{|c|c|c|c|c|c|}
\hline S.No & Force $(\mathrm{F})$ & $\mathrm{e} 1$ & $\mathrm{e} 2$ & $\begin{array}{c}\text { L1 (IL)=300 } \\
\text { Estimated final length }\end{array}$ & $\begin{array}{c}\text { L2 (IL)=310 } \\
\text { Estimated Final length }\end{array}$ \\
\hline 1 & 25 & 0.0076 & 0.0152 & 302.2800 & 314.7120 \\
\hline 2 & 30 & 0.0081 & 0.0163 & 302.4300 & 315.0530 \\
\hline 3 & 35 & 0.0086 & 0.0174 & 302.5800 & 315.3940 \\
\hline 4 & 40 & 0.0091 & 0.0185 & 302.7300 & 315.7350 \\
\hline 5 & 45 & 0.0096 & 0.0196 & 302.8800 & 316.0760 \\
\hline 6 & 50 & 0.0101 & 0.0207 & 303.0300 & 316.4170 \\
\hline 7 & 55 & 0.0106 & 0.0218 & 303.1800 & 316.7580 \\
\hline 8 & 60 & 0.0111 & 0.0229 & 303.3300 & 317.0990 \\
\hline 9 & 65 & 0.0116 & 0.0240 & 303.4800 & 317.7810 \\
\hline 10 & 70 & 0.0121 & 0.0251 & 303.6300 & \\
\hline
\end{tabular}

\section{CONCLUSION}

The doubled walled carbon nanotubes mechanical properties are investigated by adopting the Finite element modeling. The experiments were conducted with various loading conditions on both inner and outer walls of the DWCNTs. The stiffness coefficient and young's modulus of DWCNTs are supportive to analyze the elastic properties of the tubes.

In future this methodology is to be proposed to test on piezo electic transducer constructed with DWCNTs. Considering the elastic properties of the tube the DWCNTS can be used for vibration sensors positively.

\section{ACKNOWLEDGEMENT}

The authors like to express sincere thanks to the management and principal of Sai Spurthi Institute of Technology for providing the fund and necessary infrastructure.

\section{REFERENCES}

[1] Anand .Y, Joshi, " Investigation of double walled carbon nanotubes for mass sensing", Procedia technology, 2nd international conference on innovations in automation and mechatronics engineering, Vol.14: 290-294, 2014.

[2] LIFENG WANG, DONG HAN, G. R. LIU, XIANGYANG CUI," free vibration analysis of double walled carbon nanotubes using the smoothed finite element method", International journal of computational methods, Vol. 08(04), December 2011.

[3] Mahmoud Nadim Nahas, Mahmoud Abd-Rabou, "Finite Element Modeling of Multi-Walled Carbon Nanotubes", International Journal of Engineering \& Technology,Vol.10(04):63-71, 2010.
[4] Milad Hemmatnezhad, Reza Ansari, "Finite element formulation for the free vibration analysis of embedded double-walled carbon nanotubes based on nonlocal Timoshenko beam theory", Journal of theoretical and applied physics, Vol 7(6): 1-10, 2013.

[5] R.ansari, M.Hemmatnezhad, “ Non Linear finite element analysis for vibrations of double walled carbon nanotubes”, Springer science, Vol 67: 373- 383,2012.

[6] Ajay patel, Anand y jyothi, “ investigation of double walled cabon nanotubes for mass sensing", Procedia technology, Vol 1(14): 290-294, 2014.

\section{AUTHOR PROFILE}

K.Vidyasagar: Received B. Tech degree in Instrument Technology from Andhra University College of Engineering Visakhapatnam, M.E from P.S.G.Tech Coimbatore. He is now a research scholar under the guidance of Dr. A. Bhujangarao, Andhra University. His current research interests include image processing in biomedical instrumentation and related embedded systems.

Sk. Ahmadsaidulu received B.Tech from SaiSpurthi Institute of Technology, Sattupalli and M. Tech from JNTU Kakinada. $\mathrm{He}$ published several papers in various international conferences. His current research interest is embedded systems, and related communications.

T. Chaitanya : Received B. Tech degree in Electronics and Communication Engineering from Bapatla Engineering College Bapatla, M. Tech Systems and Signal processing from Adams Engineering College, Paloncha. Her current research interests including VLSI Signal Processing and related embedded systems 